\title{
Effectiveness, earmarking and labeling: testing the acceptability of carbon taxes with survey data
}

\author{
Andrea Baranzini ${ }^{1} \cdot$ Stefano Carattini $^{1,2}$
}

Received: 3 June 2015/Accepted: 21 January 2016/Published online: 24 February 2016

(C) The Author(s) 2016. This article is published with open access at Springerlink.com

\begin{abstract}
This paper analyzes the drivers of carbon taxes acceptability with survey data and a randomized labeling treatment. Based on a sample of more than 300 individuals, it assesses the effect on acceptability of specific policy designs and individuals' perceptions of carbon taxes advantages and disadvantages. We find that the lack of perception of primary and ancillary benefits is one of the main barriers to the acceptability of carbon taxes. In addition, policy design matters for acceptability and in particular earmarking fiscal revenues for environmental purposes can lead to larger support. We also find an effect of labeling, comparing the wording "climate contribution" with "carbon tax". We argue that proper policy design coupled with effective communication on the effects of carbon taxes may lead to a substantial improvement in acceptability.
\end{abstract}

Keywords Climate policy $\cdot$ Carbon tax $\cdot \mathrm{CO}_{2}$ emissions $\cdot$ Political economy

JEL Classification $\mathrm{D} 72 \cdot \mathrm{H} 23 \cdot \mathrm{Q} 48 \cdot \mathrm{Q} 52 \cdot \mathrm{Q} 58$

Stefano Carattini

stefano.carattini@hesge.ch

Andrea Baranzini

andrea.baranzini@hesge.ch

1 Haute école de gestion de Genève, HES-SO, University of Applied Sciences Western Switzerland, 7, route de Drize, Carouge, 1227 Geneva, Switzerland

2 Grantham Research Institute on climate change and the environment and ESRC Centre for Climate Change Economics and Policy, London School of Economics and Political Science (LSE), Houghton Street, London WC2A 2AE, UK 


\section{Introduction}

In recent decades, international negotiations have aimed at stabilizing the concentration of greenhouse gases at levels that would prevent dangerous interferences with the climate system. However, there is increasing evidence showing that current mitigation efforts are by large not enough (UNEP 2013; IPCC 2014). This result comes as no surprise. Even though economists assessed their theoretical cost-effectiveness long time ago (cf. e.g. Baumol and Oates 1971), the implementation of powerful policy instruments to reduce greenhouse gas emissions such as carbon taxes is a rather recent phenomenon (Baranzini and Carattini 2014). A recent strand of literature has started exploring the public acceptability of carbon taxes, pointing to a series of important obstacles such as distributional impacts on low-income households and fear of competitiveness effects (cf. Baranzini et al. 2000; Zhang and Baranzini 2004). In most developed countries carbon taxes are indeed at least slightly regressive (see e.g. Roca and Serrano 2007; Brännlund and Ghalwash 2008; Sterner 2011) and the local co-benefits benefitting mostly the poorest households are usually given a lower weight. Despite the recent empirical evidence points to rather small competitiveness effects (Mathys and de Melo 2011), potential adverse effects on employment and competitiveness represented a real concern when the first carbon taxes in Scandinavian countries were designed (cf. e.g. Godal and Holtsmark 2001; Bruvoll and Larsen 2004) and when similar schemes were turned down elsewhere (cf. e.g. Thalmann 2004).

More recently, the literature has devoted increasing attention towards the perceived impact of carbon taxes on the environment. While economists tend to take the beneficial environmental effects as granted, the effectiveness of carbon taxes does not seem to be always internalized by the general public. Based on qualitative assessments, Dresner et al. (2006) first raised the issue of perceived environmental ineffectiveness: the general public tends to miss the incentive effect of carbon taxes, thus expecting tax revenues to be earmarked for environmental purposes. When this is not the case, most people feel that carbon taxes are just a pretext to raise fiscal revenues. When tax revenues are earmarked for other purposes, the general public is generally disconcerted about the possibility of using the revenues of an environmental tax for something unrelated to the environment. Sælen and Kallbekken (2011) define this problem as "issue-linkage". The stylized fact of Dresner et al. (2006) is supported by the quantitative evidence of Kallbekken and Sælen (2011) and Sælen and Kallbekken (2011), both finding a negative pattern between perceived environmental ineffectiveness and stated support for carbon and energy taxes, and is consistent with real voting behavior as analyzed by Thalmann (2004). Pigouvian taxes are thus perceived at the same time as coercive and ineffective (Steg et al. 2006). This may lead Pigouvian taxes to be more popular if not labelled as such: in the lab experiment of Kallbekken et al. (2011), a "fee" is preferred to an equivalent instrument called "tax".

We improve this recent literature using survey data and a randomized labeling treatment to test the effect of several policy variables and perceptions on acceptability. First, we confirm that perceived environmental ineffectiveness is 
one of the main barriers to the acceptability of carbon taxes. Our original approach shows that not only the expectation of main environmental effects affects acceptability, but also the perception of potential co-benefits does. Second, we show that competitiveness and distributional effects may not have a role as determinants of acceptability. Third, we show that acceptability increases substantially with earmarking, in particular for environmental purposes. This is especially true among those individuals who tend to distrust the government. However, earmarking does not act as a substitute for perceived effectiveness. Even when revenues are earmarked, perceived effectiveness remains related to higher acceptability. Fourth, contrasting the labels "carbon tax" and "climate contribution", we show that labeling can spur acceptability also in the street and not only in the lab. "Climate contribution" may sound as an appeal to the public good, recalling to the general public the urgency of climate change mitigation.

We use the Canton of Geneva, Switzerland, as field, and interview more than 300 individuals between December 2012 and January 2013. The Swiss context may be particularly salient to simulate voting behavior, since Swiss people are used to express their opinions in poll and ballots, but we consider all of our findings of general interest. The lack of popularity of carbon taxes has indeed limited its implementation in virtually all political contexts in developed countries.

\section{Survey design and data description}

\subsection{Hypotheses}

We formulate a series of main hypotheses to be tested with the econometric model.

We expect positive perceived impacts of carbon taxes to be positively associated to carbon tax acceptability. Positive impacts consist of carbon emissions abatements (i.e. environmental effectiveness) and improvements in local outcomes such as air quality, health and road externalities. As shown by Dresner et al. (2006) and Bristow et al. (2010), the acceptability of a given carbon tax design can be influenced by how agents perceive the instrument as effective (see also Brouwer et al. 2008 on a carbon travel tax). We are not aware of previous studies examining the link between perceived co-benefits and acceptability, but Longo et al. (2012) suggest for instance that the willingness to pay for climate change mitigation is about 50-70 \% higher when co-benefits are considered by respondents.

Concerning drawbacks, distributional concerns affect acceptability in Thalmann (2004), in which the probability of a yes-vote for a green proposal is substantially lower when the proposal implies a clear increase in inequalities. Bristow et al. (2010) find a marked preference for a carbon credit up to 4 tons of $\mathrm{CO}_{2}$ per capita to reduce distributional effects. Inequality aversion is also present in Kallbekken and Sælen (2011) and Brannlund and Persson (2012).

Acceptability is supposed to increase with earmarking and we expect earmarking for environmental purposes to have the largest impact (cf. e.g. Dresner et al. 2006; Steg et al. 2006; Kallbekken and Aasen 2010; Sælen and Kallbekken 2011). When earmarking is not specified, we expect people distrusting the government to be less 
likely to approve carbon taxes. Since most people fail to understand the difference between Pigouvian and Ramsey taxes and thus perceive environmental taxes as a mean to raise more revenues (Kallbekken et al. 2011), they may be willing to give up some of their income only if the use of revenues is clearly made explicit. Because the tax is perceived as environmentally ineffective, the only way to impact the environment is by earmarking the fiscal revenues for the environment.

Based on the literature, we forecast different acceptability depending on the labeling of the tax. According to Steg et al. (2006), environmental taxes are perceived by most of the general public as "penalties", i.e. coercive measures imposing a change in behavior. Higher acceptability with different labeling is found not only in Kallbekken et al. (2011), but also in the online choice experiment of Brannlund and Persson (2012), in which a policy called "tax" is opposed to another policy simply framed as "other". To make the contrast even more manifest, in our survey we opt for the labeling "climate contribution" as opposed to "tax". We expect "climate contribution" to sound as an appeal to the public good, which may crowd in motivation as predicted by persuasive advertising models as in Becker and Murphy (1993) and Nyborg et al. (2006). "Climate contribution" may signal that the climate as we know it (i.e. the status-quo) requires help, whereas a "tax" may recall a threat to disposable income (cf. e.g. Kahneman and Tversky 2000).

Finally, we recall that most of the general public would not tackle climate change as economists would, i.e. with first-best economic instruments. Indeed, "noncoercive" policies enjoy much higher acceptability. Hence, people not considering carbon taxes as a priority to cope with climate change are expected to be less supportive of this instrument and the other way round. In sum, the hypotheses that we test in Sects. 3.1 and 3.2 are the following:

H1 Perceived positive (negative) effects of carbon taxes positively (negatively) affect carbon tax acceptability. Positive effects consist not only in emissions abatements but also of local co-benefits.

H2 Earmarking revenues increases acceptability, especially for environmental purposes.

H3 The support to carbon taxes of people not trusting the government is especially dependent on the use of revenues.

H4 The label "climate contribution", as opposed to "carbon tax", generates more support.

H5 Most people do not see carbon taxes as the main solution to curb greenhouse gas emissions. These people are less likely to support carbon taxes.

To test these hypotheses, we administer face to face a questionnaire pre-tested and supported by a qualitative study (see Sect. 2.3) to random people in the streets of Geneva. In an experimental spirit, we test for hypothesis H4 by administering two types of questionnaire: half of the sample was randomly attributed a questionnaire with the wording "carbon tax" (hereafter CT), while the remaining with "climate contribution" (CC). ${ }^{1}$

\footnotetext{
${ }^{1}$ Cf. Appendix 1 for the full questionnaires.
} 


\subsection{Economic context}

From a climate policy perspective, the context of Switzerland is of particular interest. Switzerland lobbies beside the European Union in the post-Kyoto negotiations, urging for ambitious agreements. In addition, in the aftermath of the Fukushima accident, Switzerland decided to start to phase-out nuclear energy. Since currently $40 \%$ of electricity is from nuclear sources, Switzerland has very low carbon emissions from electricity in international comparison and thus little room for maneuver to replace nuclear energy without increasing carbon emissions. This implies the need for substantial reductions in consumption (Baranzini et al. 2013).

Given the public rejection of three energy-tax proposals in 2000, Switzerland adopted a climate strategy based on voluntary agreements and only in 2008 introduced a carbon tax limited to heating fuels (cf. Thalmann 2004; Baranzini et al. 2004). After that Switzerland missed in 2012 its objective of $\mathrm{CO}_{2}$ emissions reduction, the carbon tax rate was revised upward, but an extension of the tax base to all fuels may be desirable to reach the more ambitious abatement targets currently under consideration. ${ }^{2}$ In particular we refer to the pledge that Switzerland submitted to the UNFCCC in February 2015 in view of the same year's Conference of Parties, consisting in a reduction of emissions of $50 \%$ by 2030 with respect to the levels of 1990. Doing so, Switzerland became the first country to submit a pledge and set the bar high for the following participants.

Energy taxes are already a hot topic in Switzerland. In March 2015, the Swiss population rejected at $92 \%$ (90.9\% in the Canton of Geneva) an extremely ambitious popular initiative promoted by the Green Liberals aiming at completely replacing the current value-added tax (VAT) with an energy tax. Given the substantial dependence of the Swiss government from VAT revenues and the concern that energy prices would have spiked well beyond what currently under consideration by policymakers, the promoters of the initiative found themselves practically isolated and with the government taking position against the initiative. While the Swiss government opposed the specific proposal brought up by the Green Liberals, it does support the principle of economic incentives and in particular of generalized carbon taxes. Shortly after the vote, the Swiss government announced its plan for reaching the abovementioned targets, which indeed relies on carbon taxation of all fuels (with a short embargo on gasoline) and lump-sum redistribution of revenues. In line with the findings of this paper, the Swiss government interprets the March 2015's vote as a rejection of the Green Liberals' proposal and not of carbon taxes per se.

\subsection{Qualitative survey}

To define the questions of the quantitative survey, we first administer through semistructured interviews a qualitative survey to a small and unrepresentative sample of

\footnotetext{
2 The reference tax rate at the time of the study was $60 \mathrm{CHF}$ per ton of $\mathrm{CO}_{2}$, but the government could increase it up to $120 \mathrm{CHF} / \mathrm{tCO}_{2}$ if deemed necessary. As of May $2015,1 \mathrm{CHF} \approx 1.05 \mathrm{USD} \approx 0.95 \mathrm{EUR}$. Two thirds of revenues are redistributed lump sum to households and through lower social contributions to firms. The remaining third is allocated to energy-efficiency investments in the building sector.
} 
about 40 adults living in the Canton of Geneva. The interviews took place between October 26th and November 26th 2012. We report the main findings. First, private actions (e.g. improvements in energy efficiency) are preferred to public intervention to curb energy consumption and emissions. Second, when interviewers introduce explicitly the role of the public sector, the general opinion is to limit its intervention to communication and education (i.e. suasion). Market instruments are mentioned only by few, and subsidies (e.g. for public transportation) are by large preferred to taxes, as in Cherry et al. (2012).

Third, interviewers face some resistance when they propose the implementation of a generalized carbon tax, related to distrust in the government and a presumed ineffectiveness in changing behavior. It follows that when they ask how tax revenues should be used, most respondents suggest to keep them in the environmental domain. Fourth, social cushioning for low-income households is regarded as important, but it seems that the way of financing it should be independent of the environmental tax revenues.

\subsection{Quantitative survey}

\subsubsection{Sample properties}

We administer the quantitative survey between December 14th 2012 and January 14th 2014. Our sample is composed of 338 valid observations, 158 in the CT and 180 in the CC sub-samples. Respondents are recruited in the street, with the CT and $\mathrm{CC}$ questionnaires being randomly allocated to interviewers and thus interviewees. The composition of the sample is fairly representative of Geneva population, except for a slight under- (over-)representation of retired (young) and less educated individuals. Based on the socioeconomic characteristics of Table 3, we compare the CT and CC sub-samples. We do not find any statistical differences in the averages of these variables, except in the case of education (16 years with CT compared to 15.59 with CC) and the number of adults in the households (2.15 with CT and 2.44 with $\mathrm{CC}$ ). Even though most of our insights are driven by internal validity, we are also concerned by the external validity of our results. The econometric approach of Sect. 3 takes thus care of possible sample selection.

The survey also identifies members of environmental organizations (hereafter "green members", $14 \%$ of the sample) and political positioning (coded as left, center, right and no positioning), and investigates general measures of self-reported environmental concern. It also asks whether respondents generally trust their government and if they are aware of the existing $\mathrm{CO}_{2}$ tax on heating fuels. Most of the people in the sample do trust the government as $93 \%$ declare to be either "rather confident" or "completely confident" with respect to the government's deeds. Remarkably only $40 \%$ declare to be aware of the current carbon taxation. The lack of awareness concerning current taxation may be explained by the limited salience of both taxation and lump-sum refunds to households through reduced healthcare bills. Respondents are also asked what role they would attribute to the public sector to spur energy conservation. Only a tiny fraction of individuals (2\%) contends that there is no need for energy conservation at all. Similarly, only $3 \%$ 
believe that energy consumption does not need to be regulated. That is, the large majority expects the government to intervene to curb energy consumption. However, as for the qualitative survey, market instruments do not represent the favored tool. Preferences go rather to informational campaigns raising awareness and to policies funding public transportation. However, already at this stage $35 \%$ of respondents believe that the Swiss government should intervene with a broader carbon tax to lower energy consumption.

\subsubsection{Policy variables}

In what follows we present the main policy variables included in the survey (cf. Table 5 for the full descriptive statistics).

Carbon taxes' environmental effectiveness In the survey, we introduce a hypothetical carbon tax (or climate contribution) with a tax rate of $120 \mathrm{CHF}$ per ton of $\mathrm{CO}_{2}$, implying a price increase of gasoline of about $15 \%$ and of heating fuel of about $30 \%$. The majority of the sample thinks that the tax would lead to a reduction of their level of energy consumption, but a non-negligible proportion of respondents $(37 \%)$ expects no change in behavior. A small minority (7\%) even expects larger consumption. These either represent protest answers or suggest that worries of a possible motivational crowding-out may be justified. That is, economic instruments may turn out to have counterproductive effects on intrinsically motivated agents (Deci and Ryan 1985), if individuals that already provide large efforts for a given public good in the absence of any economic incentive feel frustrated for being taxed despite their efforts ("no behavior is good enough not to be penalized", Goeschl and Perino 2012) or feel less responsible toward the provision of the public good as they think that "since I pay, I can consume and thus pollute" (Bazin et al. 2004).

Next, the questionnaire enlarges the focus and asks whether people expect the tax to be effective, i.e. if it would lead to a decrease in the energy consumption and greenhouse gas emissions of Switzerland. A short majority (52\%) expects the tax not to be effective.

Co-benefits Respondents are asked to spontaneously mention a list of ancillary benefits of carbon taxes, if any, without having access to the list of potential answers in the questionnaire, to avoid to influence their opinions. About half of the sample (56\%) expects better air quality as an ancillary benefit from carbon taxes. The proportion is lower for congestion issues $(27 \%)$, health improvements (42\%) and road accidents (18\%). People thus exhibit a relatively low awareness of co-benefits, which may need to be targeted through improved communication, along with primary benefits.

Disadvantages In line with the literature, regressive effects seem to represent a real issue for the people in this sample. However, we find that only a minority (25\%) is concerned about distributional effects on rural households, which are also expected to be particularly affected, given the limited possibilities of substitution between private and public transportation in the countryside. This may be specific to the 
context of Geneva, whose countryside hosts many high-income households attracted by calmness, green spaces and possibly low income tax rates. Instead, only relatively small proportions of respondents are concerned about employment and competitiveness effects. In particular, the number of people concerned about employment issues $(11 \%)$ is only slightly larger than those concerned about their own job ( $5 \%$; the correlation between being concerned about unemployment and being concerned about the own job is 0.46). We note that at the time of the survey, the level of unemployment in the Canton of Geneva (in Switzerland) was about $5.5 \%(3 \%)$.

Finally, one of the main perceived drawbacks is represented by the private cost of climate change mitigation, which is strictly positive for all citizens absent any redistribution. The most generalized fear for respondents in this sample $(67 \%)$ is to be constrained to reduce the overall level of consumption due to the higher energy prices. Interestingly, expecting lower purchasing power does not necessarily imply a loss of comfort. It appears that people in the sample feel that they could live comfortably even with less purchasing power, although they may not like it. Further data inspections show that expecting losses of purchasing power is negatively correlated with the highest income category and expecting less comfort is positively associated with the lowest income category.

Acceptability After discussing policy's advantages and disadvantages, we directly test for policy acceptability. No earmarking is specified at this stage, i.e. tax revenues fund the general budget, which is the first best from an economic perspective (cf. Sælen and Kallbekken 2011). The share of positive answers is quite high and close to majority (49\%). In fact, the approval rate is very close to the support given to the "Energy conservation package" in the ballot of 2000 (46.6\%, cf. Thalmann 2004). ${ }^{3}$

Social cushioning The questionnaire then asks what groups of population should be compensated due to the CT/CC perceived adverse impacts. Social cushioning is particularly warranted for low-income households (72\% of support), but around 50-60\% of respondents support also compensating measures for elderly people and large families. We stress that retiring implies lower income (60\% of preretirement income is the social security target in Switzerland) and pensions are not indexed to inflation. In the United Kingdom, for instance, lump-sum transfers are done in favor of people aged 62 or more under the Winter Fuel Payment scheme. However, cushioning of these two categories is seldom mentioned in the literature.

Societywide refunds, i.e. the current way of refunding tax revenues from the Swiss carbon tax on heating fuels, seems not to be the preferred option for our sample, although it represents a simple and cheap (but also possibly ununderstood) way of reducing regressivity (see e.g. Metcalf 2009; cf. Pezzey and Jotzo 2013 and Bristow et al. 2010 on tax thresholds). In particular, we remark that older people are

\footnotetext{
3 Respondents were also given a "Do not know" option. However, what we want to assess is the willingness to accept such a policy and hence treat irresolute respondents as no-voters, although abstention is always an alternative in ballots. 93 individuals are concerned.
} 
disadvantaged by the current recycling, while the opinions in this sample would rather justify a specific aid to this sub-population.

Revenue recycling We propose three ways of revenue recycling (and give space for a possible fourth option). The first option is redistribution towards affected households, which relates to the previous discussion on distributional effects. The second option consists in tax rebates for households and firms, which may allow, by decreasing distortionary taxes, for the double dividend of environmental taxation. Earmarking tax revenues for environmental purposes is a recurrent and popular option in the literature and represents the third alternative. Respondents are asked to rank the alternatives in decreasing order of preference. Unsurprisingly, $60 \%$ of the respondents would like to see the tax revenues used to finance environmental projects. Social cushioning comes second, while tax rebates to households and firms are supported by a small minority only.

Acceptability conditional on recycling We retest the level of acceptability conditional on earmarking and revenue recycling. In detail, the survey asks whether the respondent would accept a CT/CC if revenues were to be recycled according to her preferred recycling option. Yes-votes reach now $64 \%$, i.e. about $15 \%$ more than without earmarking. This result is consistent with the literature. This level of support may however be misleading since obtained by assuming that the preferred recycling options of each individual can be implemented simultaneously. We also stress the relative importance of the residual $36 \%$ of respondents for which earmarking revenues is not sufficient to have them accepting the CT/CC, at least at the tax rate proposed by the questionnaire. Econometric analyses are performed in Sect. 3 .

Tax rate So far, the questionnaire refers to a CT/CC with a tax rate of $120 \mathrm{CHF} /$ $\mathrm{tCO}_{2}$, causing with full pass-through an increase of about $15 \%(30 \%)$ in the price of gasoline (heating fuels). The questionnaire, thus, asks to the respondents what would be their highest acceptable CT/CC tax rate, expressed in terms of energy price increases. The aim is to measure the intensity of acceptability. The distribution of answers is bounded by the minimum and maximum possible answers given in the questionnaire (0 and $30 \%$ ) and centered in the 5-10\% interval (using interval means, the average is $7 \%$ and the median $7.5 \%$ ). Hence, albeit $64 \%$ of the sample supports the tax in the previous question, when asked about defining themselves the tax rate, respondents tend to indicate more moderate energy price increases than what proposed by the survey. The two results are not necessarily in contradiction. Voters are indeed supposed to select the option that is closer to their preferences. In this respect, the Norwegian choice experiment of Sælen and Kallbekken (2011) shows that respondents would prefer to decrease the current level of environmental taxes, absent earmarking for environmental purposes. In a similar spirit, Godal and Holtsmark (2001) suggest to always start with a low tax rate and increase it regularly once the policy is in place. 


\section{Econometric analysis, results and discussion}

\subsection{Carbon tax acceptability}

In this section, we analyze the determinants of carbon tax acceptability when earmarking is not specified. Since the outcome variable is binary, we apply a probit estimation strategy. We use as controls both socioeconomic characteristics and the policy perceptions presented in the previous section. Several socioeconomic factors are possible determinants of the demand for environmental policy in general and climate change mitigation in particular. We obtain from our survey data on e.g. income, education, age, gender, car holding (as proxy for carbon footprint, see Thalmann 2004; Kallbekken and Sælen 2011; Diederich and Goeschl 2013) and membership of environmental organizations (as proxy for pro-environmental behavior).

Estimations results are reported in Table 1, based on marginal effects at median, consistently with the median voter theorem. ${ }^{4}$ Column (1) starts with socioeconomic characteristics.

Given the many missing values and its statistical non-significance, income is excluded. A variable taking value 1 if income is missing would also be nonsignificant. The absence of an effect of income is in line with the literature on environmental ballots (see e.g. Deacon and Shapiro 1975; Thalmann 2004; Bornstein and Lanz 2008) and fits the theoretical prediction, above all in a global context in which the demand for environmental quality is likely to be only partially expressed (cf. Roca 2003).

Some other socioeconomic variables are clearly not significant. We do not find for instance any statistically significant effect for age (both as a continuous variable or using specific groups such as e.g. youth, retired people), gender and political positioning.

Column (1) shows that the number of cars held by respondents is negatively and significantly linked with the probability of accepting a carbon tax, whereas green membership and education have a positive impact. That is, as in Thalmann (2004), it is not only car ownership, but also the number of vehicles that is related to political behavior. Of course, ecologists are expected to be relatively more in favor of climate policy tightening. The effect of education is also as predicted. Since education is a long-run investment, educated people may possess a lower discount rate than the average citizen, according to Bornstein and Lanz (2008). Moreover, educated people may suffer of lower informational gaps on climate change issues.

\footnotetext{
${ }^{4}$ Marginal effects are derivatives computed in different ways depending on the assumed underlying distribution. Probit assumes a normal (Gaussian) distribution. We compare marginal effects at median with marginal effect at mean, average marginal effects, logit (which allows for "thicker tails") and OLS. Marginal effects at mean and average marginal effects are qualitatively unchanged with respect to the estimates presented in the tables (estimates not provided here). We find that for most coefficients the choice of the econometric model has implications for the interpretation in terms of magnitude, but not of sign and significance. In a few specifications co-benefits turn out to be non-significant. Given the presence of heteroscedasticity, the estimated model includes a heteroscedastic error term. Standard errors are computed with the Delta method (cf. Greene 2011). We report estimations for our preferred models, but the insights provided in this section generally hold also with the alternative specifications.
} 
Table 1 Testing carbon tax/climate contribution acceptability: marginal effects at median from probit estimation

\begin{tabular}{|c|c|c|c|}
\hline $\begin{array}{l}\text { Acceptability when earmarking } \\
\text { is not specified }\end{array}$ & (1) & (2) & (3) \\
\hline Number of cars & $-0.0935^{* *}(0.0411)$ & $-0.0540 *(0.0323)$ & $-0.0641 *(0.0340)$ \\
\hline Green member & $0.267 * * *(0.0790)$ & $0.212 * *(0.0943)$ & $0.196^{* *}(0.0925)$ \\
\hline Years of education & $0.0286 *(0.0162)$ & $0.0144(0.0159)$ & $0.0166(0.0173)$ \\
\hline Gender (male) & $0.0827(0.0589)$ & & \\
\hline Number of adults in the household & $0.0284(0.0283)$ & & \\
\hline Homeowner & $0.0437(0.0853)$ & & \\
\hline Age & $0.000629(0.00227)$ & & \\
\hline Unemployed & $-0.0596(0.189)$ & & \\
\hline Left & $0.134(0.0836)$ & & \\
\hline Center & $0.0681(0.0786)$ & & \\
\hline Right & $-0.0533(0.0902)$ & & \\
\hline Climate: high concern & & $0.164 * * *(0.0616)$ & $0.146^{* *}(0.0673)$ \\
\hline Energy consumption: no attention & & $-0.339 * * *(0.126)$ & $-0.377 * * *(0.097)$ \\
\hline Energy consumption: very attentive & & $-0.0483(0.0785)$ & \\
\hline Expected cooperation & & $0.110 *(0.0624)$ & $0.0675(0.0665)$ \\
\hline Trust in the government & & $0.200 *(0.112)$ & $0.129(0.133)$ \\
\hline $\begin{array}{l}\text { Government intervention: } \\
\text { information }\end{array}$ & & $0.103(0.0707)$ & $0.126^{*}(0.0708)$ \\
\hline Government intervention: taxation & & $0.267 * * *(0.0635)$ & $0.234 * * *(0.0693)$ \\
\hline Government intervention: subsidies & & $0.0144(0.0649)$ & \\
\hline Government intervention: none & & $0.0861(0.211)$ & \\
\hline CT/CC: effect on own behavior & & & $0.186 * *(0.0734)$ \\
\hline $\begin{array}{l}\text { CT/CC: crowding-out or protest } \\
\text { answers }\end{array}$ & & & $-0.0311(0.128)$ \\
\hline CT/CC: environmental effectiveness & & & $0.283 * * *(0.0672)$ \\
\hline CT/CC: co-benefits & & & $0.0387 * *(0.0174)$ \\
\hline $\begin{array}{l}\text { CT/CC: drawbacks (less purchasing } \\
\text { power) }\end{array}$ & & & $-0.165 * *(0.0778)$ \\
\hline CT/CC: drawbacks (less comfort) & & & $-0.0286(0.0663)$ \\
\hline $\begin{array}{l}\text { CT/CC: drawbacks (fear of losing } \\
\text { job) }\end{array}$ & & & $-0.237(0.172)$ \\
\hline $\begin{array}{l}\text { CT/CC: drawbacks (distributional } \\
\text { effects on the poor) }\end{array}$ & & & $-0.096(0.0658)$ \\
\hline $\begin{array}{l}\text { CT/CC: drawbacks (distributional } \\
\text { effects on rural) }\end{array}$ & & & $-0.0966(0.0773)$ \\
\hline $\begin{array}{l}\text { CT/CC: drawbacks (competitiveness } \\
\text { effects) }\end{array}$ & & & $-0.0702(0.0843)$ \\
\hline $\begin{array}{l}\text { CT/CC: drawbacks (employment } \\
\text { effects) }\end{array}$ & & & $-0.0352(0.123)$ \\
\hline Labeling (climate contribution) & & & $-0.1253(0.1799)$ \\
\hline
\end{tabular}


Table 1 continued

Acceptability when earmarking is not specified

\begin{tabular}{llll}
\hline Pseudo $R^{2}$ & 0.075 & 0.175 & 0.282 \\
Log pseudolikelihood & -205.772 & -185.675 & -161.774 \\
$N$ & 321 & 325 & 325 \\
\hline
\end{tabular}

Robust standard errors in parentheses. * $p<0.1, * * p<0.05$, *** $p<0.01$

$H_{0}$ : all $\beta$ equal to zero. In column (1) $\mathrm{Chi}^{2}(11)=37.03, p=0.0001$. In column (2) $\mathrm{Chi}^{2}(12)=62.43$, $p=0.0000$. In column (3) $\mathrm{Chi}^{2}(21)=95.10, p=0.0000$

Lack of information could downplay the relative benefits of climate change mitigation (cf. e.g. Cohen and Viscusi 2012). The coefficient of column (1) implies that an additional year of education is linked with about $3 \%$ more probability of accepting the tax, thus mirroring the evidence on ballots (cf. Thalmann 2004; Sciarini et al. 2007; Bornstein and Lanz 2008; Bornstein and Thalmann 2008; Stadelmann-Steffen 2011) and on the demand for climate change mitigation (see e.g. Roe et al. 2001; Achtnicht 2012; Loeschel et al. 2013).

In column (2) we introduce variables on environmental attitudes. This allows us to test the hypotheses $\mathrm{H} 3$ and $\mathrm{H} 5$. We find that being a priori in favor of a carbon tax has a very large effect on acceptability. This confirms H5 and provides evidence for the internal validity in the questionnaire. As expected, trust in the government engenders higher acceptability, providing first evidence in favor of $\mathrm{H} 3$.

We also find that being highly concerned about the climate and paying no attention to energy consumption have a significant and economically meaningful impact on acceptability, consistently with Kallbekken and Sælen (2011). Since the effect of education disappears once introduced the role of information and concern, we may suggest that its effect is rather driven by information asymmetry than a difference in discounting. Expectation of cooperation in energy conservation's efforts from fellow-citizens is associated with a positive effect on acceptability. This result suggests that people's willingness to contribute to climate change mitigation may depend on others doing the same, a result increasingly found in the literature (see Carattini 2015 for a detailed review). For instance, using different treatments Bolsen et al. (2014) show that the propensity of American students to be in favor of a carbon tax depends positively on the same propensity for the whole population as reported in polls. In the same vein, Lindman et al. (2013) find that Swedish students show larger willingness to pay for climate change mitigation when provided with information suggesting a very high participation of the Swedish population in voluntary carbon offsetting activities. From a theoretical perspective, these findings, including ours, point to conditional cooperation in the climate commons (see Nyborg et al. 2006). As suggested by Ostrom (2009), individuals may be willing to contribute to a public good such as climate change mitigation if they expect others doing the same, and this in spite of the global public good property of climate change. Hence, trust may contribute to overcome some of the incentives to free ride not only in local environmental dilemmas, but also in global commons, such as 
climate change. In this respect, we refer to the recent empirical evidence providing support in favor of Ostrom (2009), with trust being negatively associated to greenhouse gas emissions (Carattini et al. 2015) and trust being positively correlated with the probability of implementing local sustainable policies under the Agenda 21 scheme (Owen and Videras 2008).

Column (3) introduces the policy variables. The coefficients of column (2) are generally robust to this new specification. "Government: information" now reaches significance, suggesting the perception of a complementarity between information and taxation. According to the focus group of Kallbekken and Aasen (2010), the general public feels that information campaigns should accompany the implementation of climate policy providing knowledge on its instruments and not only raising awareness on climate change (see also Nyborg et al. 2006; Brannlund and Persson 2012).

Column (3) allows us to further test our main hypotheses. The effects related with environmental effectiveness and perceived co-benefits are striking and partly confirm H1. If the tax is expected to be effective in reducing emissions, acceptability rises by about $30 \%$. The impact of co-benefits on acceptability has a similar magnitude, since this variable ranges from 0 to 8 . Hence, our findings strongly support the literature on the perceived effectiveness of carbon taxes and provide a quantitative estimate of the magnitude of its linkage with acceptability, which is shown to depend also on perceived co-benefits. ${ }^{5}$

Neglecting co-benefits would clearly imply an overestimation of the net policy costs, since most studies providing monetary estimates of co-benefits suggest that they are relatively conspicuous compared to mitigation costs, also in the case of Switzerland and other developed countries (cf. e.g. OECD 2014). In fact, co-benefits are in the order of several tens of dollars per ton of $\mathrm{CO}_{2}$ and may well exceed abatement costs (Baranzini and Carattini 2014). According to Pittel and Rübbelke (2008), co-benefits may be sufficiently large to justify cooperation in international negotiations and lead to binding international agreements, of course provided that their existence (and magnitude) is recognized. That is, co-benefits may be a game changer in the political economy of climate change mitigation, if fully internalized in people's beliefs.

Regarding policy drawbacks, all included variables have the expected negative sign, but only loss of purchasing power is significant. Being one of the $67 \%$ of the sample affirming that carbon taxes are an issue for purchasing power is linked with about $15 \%$ lower probability of accepting the instrument. The concern of losing purchasing power makes sense in particular given that at this stage the use of tax revenues is not specified. However, this concern may vanish over time after that the carbon taxes are implemented, since the real effect of loss in consumption on wellbeing may be lower than actually perceived, as income relative to others may be rather unchanged (Gowdy 2008, see also Howarth 2006).

\footnotetext{
5 The coefficient for crowding-out of intrinsic motivation or protest answers does not attain statistical significance. This may suggest that what we face is indeed some motivational crowding-out rather than simply protest, although with no impact on acceptability.
} 
Regressive impacts do not seem to matter in this context. Distributional effects are an issue for an important number of individuals as indicated in the descriptive statistics, but fail to significantly impact acceptability. This result differs from those of most of the literature but provides quantitative evidence for one of the finding from the focus group of Kallbekken and Aasen (2010), which stress that respondents seem to be concerned by distributional effects, but not enough to pretend environmental taxes not to be regressive.

Competitiveness and employment effects are clearly non-significant. We see four possible explanations for their non-significance. First, individuals may not be concerned about competitiveness issues, consumers having different interests than firms, and about unemployment, since they may have very small empathy for potential jobless and perhaps limited fear of how rising levels of unemployment could affect their own situation. However, this may be in contradiction with the evidence based on voting behavior of Thalmann (2004), in which concern about employment issues contributed to the rejection by the Swiss population of three energy tax proposals in spite of an unemployment rate below $2 \%$. Second, individuals may not expect competitiveness effects to be sufficiently large to become a real problem. This may make sense in the light of the modeling exercise of Sceia et al. (2012), which find very limited terms-of-trade effects for Switzerland when simulating the impact of unilateral moves towards more stringent climate policy. Third, respondents may expect Swiss climate policy to be part of a concerted move undertaken with other countries, e.g. under the umbrella of a renewed Kyotolike agreement. In such scenario, terms-of-trade effects as modeled by Sceia et al. (2012) become positive. Fourth, the very low concern for employment and competitiveness effects may also be due to the low profile of corporate interest groups at the time of the survey. Indeed, once approaching important votes, the latter tend to employ massive lobbying efforts to have their vested interests internalized by the public, leading the industry flight argument to gain a very important weight in the political discourse (Spash and Lo 2012). This interpretation would call for green lobbying to oppose the industry flight argument and preserve the current outcome (see Dietz et al. 2012).

Altogether, this evidence may question the rationale for the large exemptions and privileges given to some industries by the carbon schemes of some Scandinavian countries or Australia, which have eventually watered down the environmental impact of the tax itself (see Lin and Li 2011; Baranzini and Carattini 2014). Partially rejecting H1, Table 1 suggests that the popularity of carbon taxes may not necessarily imply a trade-off between environmental, distributional and competitiveness effects.

Labeling is not significant at this stage. Regarding the relative performance of the three specifications of Table 1, we see that the goodness-of-fit increases as more variables are added, confirming that policy perception does matter for acceptability, beside individual characteristics. 


\subsection{Impact of earmarking on carbon tax acceptability}

In this section, we focus on the individuals that do not accept the policy proposal in Sect. 3.1 and examine whether their choice changes conditional on the implementation of their preferred option of revenue recycling. The variable to be explained takes value 1 for those changing opinion in favor of the CT/CC and 0 otherwise. We then rely again on a probit model, conditional on choosing 0 in the first acceptability question. We select the least chosen option, tax rebates to households and firms, as the reference case.

The estimation reported in Table 2 includes variables for revenue recycling and labeling, now significant. The literature gives no priors on the potential impact of socioeconomic characteristics on acceptability conditional on the preferred use of tax revenues. We find that in general none is statistically significant, except for a positive effect again of education ( $p$ value of 0.098). Policy variables seem instead confirming our set of hypotheses. Trust in the government is associated with a negative sign and a fairly large coefficient. This makes sense in the light of the positive coefficient in Table 1 . That is, trust in the government is positively associated with being in favor of the CT/CC regardless of how tax revenues are used, whereas respondents distrusting the government are relatively more likely to reject the first proposal and potentially change opinion in Table 2, once revenues are earmarked. Hence, we can confirm hypothesis H3.

Compared to the rest of respondents, those suggesting that the government should address the issue of energy consumption with taxation do not have a higher probability to change their opinion with earmarking. This is consistent with the result of Table 1 and hypothesis H4. In contrast, those asking the government to better communicate the need and possibilities for energy conservation are, everything else equal, more likely to support the tax both unconditionally and conditionally on earmarking. This may point again to the complementarity between taxation and communication.

The effect of perceived effectiveness is in line with our hypothesis. Expecting the tax to work is linked to a positive effect on acceptability, also among those that rejected the first CT/CC proposal. As suggested by the qualitative analysis of Kallbekken and Aasen (2010), being aware of how the incentive effect works does not necessarily imply no demand for earmarking. The marginal effect in Table 2 is still pretty large and implies that in this sub-sample the likelihood of voting yes once the use of revenue is defined is about $25 \%$ larger for those believing the CT/CC to work than for those that do not. On top of that, there seems to be again a positive effect of co-benefits.

We observe that the probability of reconsidering the CT/CC is larger for those selecting recycling for environmental purposes than for those opting for tax rebates (the dummy of reference), everything else equal. The coefficient for recycling through social cushioning (as defined by the respondent) is not statistically significant. Therefore, it seems that earmarking for environmental purposes really matters for acceptability, confirming hypothesis $\mathrm{H} 2$. Since we control for e.g. trust in the government and perceived effectiveness, we relate this demand for environmental recycling with the issue-linkage, i.e. the need for the public to see 
Table 2 Carbon tax/climate contribution acceptability with earmarking and revenue recycling: marginal effects at median from probit estimation

\begin{tabular}{|c|c|}
\hline Acceptability when earmarking is specified & (1) \\
\hline Number of cars & $0.0753(0.0652)$ \\
\hline Green member & $0.0182(0.192)$ \\
\hline Years of education & $0.0392 *(0.0236)$ \\
\hline Gender (male) & $0.0695(0.0956)$ \\
\hline Number of adults in the household & $0.0208(0.0447)$ \\
\hline Homeowner & $-0.0912(0.121)$ \\
\hline Age & $0.00183(0.00373)$ \\
\hline Unemployed & $0.219(0.275)$ \\
\hline Left & $0.213(0.162)$ \\
\hline Right & $0.119(0.131)$ \\
\hline Expected cooperation & $0.0616(0.0901)$ \\
\hline Trust in the government & $-0.341 * *(0.149)$ \\
\hline Government intervention: information & $0.157 *(0.0925)$ \\
\hline Government intervention: taxation & $0.130(0.115)$ \\
\hline CT/CC: environmental effectiveness & $0.256 * *(0.0996)$ \\
\hline CT/CC: co-benefits & $0.0461 *(0.0266)$ \\
\hline CT/CC: drawbacks (less purchasing power) & $0.120(0.101)$ \\
\hline CT/CC: drawbacks (less comfort) & $0.0385(0.0964)$ \\
\hline CT/CC: drawbacks (fear of losing job) & $-0.437 * *(0.192)$ \\
\hline CT/CC: drawbacks (distributional effects on the poor) & $-0.00170(0.0966)$ \\
\hline CT/CC: drawbacks (distributional effects on rural) & $-0.123(0.102)$ \\
\hline CT/CC: drawbacks (competitiveness effects) & $-0.126(0.122)$ \\
\hline CT/CC: drawbacks (employment effects) & $0.201(0.155)$ \\
\hline Revenue recycling: social cushioning & $0.0813(0.129)$ \\
\hline Revenue recycling: environmental projects & $0.230 *(0.126)$ \\
\hline Labeling (climate contribution) & $0.168 *(0.0903)$ \\
\hline Pseudo $R^{2}$ & 0.211 \\
\hline Log pseudolikelihood & -82.128 \\
\hline$N$ & 152 \\
\hline
\end{tabular}

Robust standard errors in parentheses. * $p<0.1, * * p<0.05, * * * p<0.01$

$H_{0}$ : all $\beta$ equal to zero. $\mathrm{Chi}^{2}(26)=47.97, p=0.0054$

a straightforward and logical nexus between the tax and the use of revenues (Sælen and Kallbekken 2011). At a given tax rate as in this context, this implies larger abatements, indicating that acceptability tends to go hand in hand with effectiveness (cf. Steg and Vlek 2009).

Hence, this result may contribute to explain why many environmental taxes earmark revenues for environmental purposes, as reported e.g. in the "Database on instruments used for environmental policy" of the Organisation for Economic Co- 
operation and Development (OECD). For instance, substantial portions of revenues from local pollution charges are earmarked for environmental improvements in Czech Republic, Estonia, Japan, Poland, Slovak Republic, Turkey and in most Spanish regions, as well as in Quebec. Part or all the revenues from carbon taxes similar to the one proposed in the survey are (or were) used for environmental purposes in several instances, including Quebec's hydrocarbon duty, Boulder's carbon tax (see Hahn 2009) and the former Australian carbon tax. Absent any counterfactual, it is yet not possible to know whether such taxes could have been implemented without earmarking. However, the presence of so many cases of environmental earmarking seems supporting the existence of a worldwide demand for this kind of use of revenues and enhance the general relevance of the political economy argument behind hypothesis $\mathrm{H} 2$.

Finally, we observe that labeling has an impact on acceptability, since the coefficient for CC (versus CT) is now significant. The fact that the $\mathrm{CC}$ treatment affects acceptability as well as revenue recycling may hint that the term "climate contribution" may not suffice to overcome some general suspicion in the first acceptability question, but it does increase support when earmarking is made explicit. An explanation may be that as introduced by the survey, both the CT and the CC look really like taxes. However, once revenues are earmarked for the environment, the $\mathrm{CC}$ may become much more appealing as it really looks as a contribution to the climate, whereas the tax still carries the unfortunate "tax" labeling. While hypothesis H4 is here confirmed, chances of wording to matter may decrease in the political arena, with repeated debates and the intervention of political parties, although based on Swiss data Buetler and Maréchal (2007) call for evidence of a framing effect in voting behavior. In this respect, we note with interest that since 2015 the Swiss government publicly refers to a "climate levy" to replace and widen the scope of its current carbon tax. In doing so, the Swiss government seems to have been inspired by the implementation of the Climate Change Levy in 2001 in the United Kingdom. Again, no counterfactual exists illustrating the popularity of a similar energy tax going under a different name. Yet, based on our findings and similar results in the literature, we can suppose that the decision to name the British scheme of energy taxes "Climate Change Levy" likely did no harm in terms of popularity, and perhaps contributed to its implementation and longevity.

\section{Conclusion}

Carbon taxes are an effective instrument for curbing greenhouse gas emissions, yet are seldom implemented (Baranzini and Carattini 2014). This paper uses survey data to assess drivers and barriers to public acceptability of carbon taxes. Albeit the political discourse generally focuses on the negative impacts on competitiveness and distributional effects (cf. e.g. Spash and Lo 2012), the data analyzed here indicate that individuals are more concerned by the environmental effectiveness of 
the tax. Indeed, we show that perceived environmental effectiveness and expectation of local co-benefits are the main drivers of acceptability. Competitiveness effects are almost completely neglected, whereas distributional issues (in particular regarding poor households) seem to represent a real concern for the general public, but with little impact on acceptability.

According to our findings, communicating both primary and ancillary benefits of carbon taxes seems to be essential for improving acceptability. Along with earmarking, this could be very useful to reduce the opposition related to mistrust in the government and Ramsey-type tax aversion (see Kallbekken et al. 2011). In this respect, we find that in terms of acceptability the best way of recycling the tax revenues is to give the priority to environmental spending. In the same vein, we also provide evidence that using a different label, viz. "climate contribution" rather than "carbon tax", can be beneficial in terms of acceptability.

Therefore, our empirical findings provide evidence that with appropriate design the chances for climate policy tightening could be substantially improved. To the extent that extrapolation from our data is possible, our results would hint that the Swiss population may accept relatively ambitious energy and climate policy of the kind it rejected in 2000, provided that policies are properly conceived and advertised. The evidence that we provide may also guide policymaking in other contexts in which the popularity of policies matter for their chances of implementation. The European experience of environmental taxation and in particular of the (planned) environmental tax reform indicates that a considerable level of popularity is a requirement for implementation in virtually all contexts (see the special issue introduced by Dresner et al. 2006). Transposability of survey estimates to political support and actual voting needs however to take into account the room for hypothetical bias and variation in timing, which is linked to media coverage, lobbying and business-cycle effects.

Acknowledgments The authors thank the Laboratory of Market Studies (LEM) at the Haute Ecole de Gestion de Genève for the valuable support. We are also grateful to two anonymous referees and Jeroen van den Bergh, Richard Howarth, Boris Krey, Emilio Padilla, Jordi Roca, Philippe Thalmann, Frédéric Varone and Frank Vöhringer for excellent comments and helpful discussion. The usual disclaimer applies. Financial support from the Swiss Federal Office of Energy is acknowledged.

Open Access This article is distributed under the terms of the Creative Commons Attribution 4.0 International License (http://creativecommons.org/licenses/by/4.0/), which permits unrestricted use, distribution, and reproduction in any medium, provided you give appropriate credit to the original author(s) and the source, provide a link to the Creative Commons license, and indicate if changes were made.

\section{Appendix 1: Questionnaires}

The original questionnaires were in French. They are available by the authors upon request. As in French and for labeling purposes, we use the term "tax" for the carbon tax of the CT sub-sample. However, it could be called "levy". 
A. Energy consumption

1. Do you try to keep your energy consumption under control?

Yes, a lot

Yes, I do

Not really

Not at all

2. Do you think that you should consume less energy?

(multiple answers)

Yes, to save money

Yes, to help the climate and the environment

Yes, if other people do it too

Yes, if other countries do it too

$\square$ No, I see no reasons to consume less energy

$\square$ No, I do my best already

3. How much (in \%) should the price of the following energy carriers increase to lead you to consume $10 \%$ less of it?

Gasoline:

Electricity:

Heating fuel:

4. Do you expect other people in Switzerland to be willing to reduce their energy consumption?

Yes

No

I do not know 
5. Do you expect other countries to be willing to reduce their energy consumption?

Yes

No

I do not know

6. In your opinion, should the Swiss government intervene to stimulate energy conservation?

Yes, by providing information and raising awareness

Yes, by subsidizing public transportation

Yes, by taxing $\mathrm{CO}_{2}$ emissions

No, this is beyond its scope

I do not care of energy conservation

I do not know

7. In your opinion, in the next 10 years, the following energy prices will:

$\begin{array}{lll}\text { Gasoline } & \text { Increase of }{ }_{-}(\%) \text { Stay constant } & \text { Decrease of }{ }_{-}(\%) \\ \text { Electricity } & \text { Increase of } \_(\%) \text { Stay constant } & \text { Decrease of } \_(\%) \\ \text { Heating fuel } & \text { Increase of }{ }_{-}(\%) \text { Stay constant } & \text { Decrease of _ }(\%)\end{array}$

8. Which of the following factors do you expect to lead to an increase in energy prices?

Yes No Do not know

Climate policy tightening

Scarcity

Nuclear exit

Expensive renewable energy

Other (please specify) 
9. In your opinion, what policy may be needed to cope with higher energy prices? (multiple answers)

Improved communication (e.g. sav- $\square$ Tax rebates for low-income houseing tips) holds

Subsidies for all households

Tax rebates for rural households

Subsidies for low-income households

Investments in public transportation

Subsidies for rural households

None of these

Tax rebates for all households

Other (please specify)

B Carbon tax/Climate contribution

We are now going to ask you a series of questions on a $\mathrm{CO}_{2}$ tax/climate contribution. This tax/contribution engenders an increase in the price of energy from fossil sources. Imagine a $\mathrm{CO}_{2} \mathrm{tax} /$ climate contribution of $120 \mathrm{CHF} / \mathrm{tCO}_{2}$ on all fossil fuels, which would imply an increase in the price of gasoline and heating fuels of about 30 cents/liter (more or less $15 \%$ of current gasoline price and $30 \%$ of current heating oil price).

10. Would this $\mathrm{CO}_{2}$ tax/climate contribution modify your energy conservation efforts?

Less efforts

No change

More efforts

11. Do you think that this $\mathrm{CO}_{2}$ tax/climate contribution would allow for a reduction in the amount of energy consumed by the Swiss population?

Yes

No

I do not know 
12. What are in our opinion the benefits of a $\mathrm{CO}_{2}$ tax/climate contribution?

(do not show the answers to respondents, see what they mention spontaneously; multiple answers)

$$
\text { For you For the society }
$$

Lower $\mathrm{CO}_{2}$ emissions

Better air quality

Less road congestion

Better health

Less road accidents

None

Other (please specify)

13. What are the drawbacks of this $\mathrm{CO}_{2}$ tax/climate contribution for your household? (multiple answers)

Loss of purchasing power

Loss of comfort

Fear of losing job
No drawbacks

Other (please specify)

14. What are the drawbacks of this $\mathrm{CO}_{2}$ tax/climate contribution for the Swiss society?

Loss of purchasing power

Loss of competitiveness

Detrimental effects on low-income households
Higher inequalities between urban and rural areas

No drawbacks

Other (please specify)

15. In spite of drawbacks, is the implementation of such tax/contribution acceptable?
$\square$ Yes
$\square$ No
$\square$ I do not know 
16. In your opinion, should the government offset the detrimental effects of such $\mathrm{CO}_{2}$ tax/climate contribution on the following groups?

$$
\text { Yes No }
$$

Low-income households (<50'000 CHF gross/year)

Middle-income households (50'000-100'000 CHF gross/year)

High-income households (>100'000 CHF gross/year)

Rural households

Urban households

Large families

Elderly people

Firms

17. Please rank in a decreasing order of preference the following ways to use the revenues from the $\mathrm{CO}_{2}$ tax/climate contribution.

Social cushioning in favor of most affected households

Tax rebates for households and firms

$\square$ Funding environmental projects, including subsidies to renewable energy

$\square$ Other (please specify)

18. If the revenues from the $\mathrm{CO}_{2}$ tax/climate contribution were to be used as you indicate in the questions 16 and 17, would you accept this $\mathrm{CO}_{2}$ tax/climate contribution?

Yes

$\square$ No

I do not know 
19. If in 6 months from now you were asked to vote on a $\mathrm{CO}_{2}$ tax/climate contribution, what is the price increase in fossil fuels that you would be willing to accept?
$0 \%$
$15-20 \%$
$0-5 \%$
$20-25 \%$
$5-10 \%$
$25-30 \%$
$10-15 \%$
$30 \%$

20. Does it exist in Switzerland a $\mathrm{CO}_{2}$ tax on heating fuels?
Yes
No
$\square$ I do not know

C. General information

21. You are:
Female
Male

22. Birth year:

23. Postcode:

24. How many people are in your household (including the respondent)?

Number of adults:

Number of children (less than 18 years):

25. Currently you are:

Homeowner

Renter 
26. How many cars does your household own?
$\square 0$
3
1
4 or more
2

27. Are you member of one or more environmental organizations?

Yes

No

28. In your opinion, protecting the environment is a:

Urgent matter

Important matter, but not a priority

Not urgent at all

29. What is your degree of trust in the Swiss government?

Not confident at all

Rather not confident

Rather confident

Completely confident

30. Your current professional status is:

Homemaker

Student

Employee

Manager

Senior manager
Self-employed

Retired

Jobless

Other (please specify) 
31. What level of education did you reach? If you are currently studying, please select the level of education corresponding to the highest diploma you already hold.
Compulsory schooling
Professional education
Apprenticeship
University of applied sciences
College
University

32. How would you locate yourself on the left-right axis?
Left
Center
Right
No answer

33. What is your household's yearly gross income?
$<25^{\prime} 000 \mathrm{CHF}$
125’000-150'000 CHF
25’000-50'000 CHF
$>150$ '000 CHF
50’000-75’000 CHF
No answer
100'000-125'000 CHF

\section{Appendix 2: Tables}

See Tables 3, 4 and 5.

Table 3 Socioeconomic characteristics: sample's summary statistics

\begin{tabular}{lllccc}
\hline Variable & Mean & Std. dev. & Min. & Max. & $N$ \\
\hline Gender (male) & 0.521 & 0.5 & 0 & 1 & 336 \\
Age & 36.860 & 14.04 & 19 & 85 & 336 \\
Years of education & 15.782 & 1.935 & 11 & 18 & 330 \\
Categories of income & 4.029 & 1.816 & 1 & 7 & 239 \\
Labor market (active) & 0.949 & 0.221 & 0 & 1 & 332 \\
Number of adults in the household & 2.306 & 1.194 & 0 & 6 & 337 \\
Number of kids in the household & 0.333 & 0.681 & 0 & 4 & 291 \\
Homeowner & 0.223 & 0.417 & 0 & 1 & 336 \\
Number of cars & 1.279 & 0.957 & 0 & 4 & 337 \\
\hline
\end{tabular}


Table 4 Environmental attitudes and behavior: summary statistics

\begin{tabular}{lll}
\hline Variable & Mean & $N$ \\
\hline Energy consumption: very attentive & 0.2 & 337 \\
Energy consumption: attentive & 0.53 & 337 \\
Energy consumption: not very attentive & 0.22 & 337 \\
Energy consumption: not attentive at all & 0.05 & 337 \\
Saving energy: to save money & 0.77 & 338 \\
Saving energy: for the environment & 0.59 & 338 \\
Saving energy: other people & 0.06 & 338 \\
Saving energy: other countries & 0.06 & 338 \\
Saving energy: no reasons & 0.06 & 338 \\
Saving energy: the best already & 0.07 & 338 \\
Elastic: gasoline & 23.40 & 292 \\
Elastic: electricity & 27.68 & 297 \\
Elastic: heating fuels & 24.59 & 288 \\
Expected cooperation & 0.76 & 242 \\
Expected foreign cooperation & 0.52 & 247 \\
Government intervention: information & 0.73 & 337 \\
Government intervention: public transportation & 0.61 & 338 \\
Government intervention: taxation & 0.35 & 338 \\
Government intervention: unnecessary & 0.03 & 338 \\
Government intervention: irrelevant & 0.02 & 337 \\
Future prices: gasoline & 27 & 331 \\
Future prices: electricity & 16 & 334 \\
Future prices: heating fuels & 18 & 335 \\
Drivers: climate policy & 0.58 & 337 \\
Drivers: scarcity & 0.89 & 337 \\
Drivers: nuclear exit & 0.5 & 337 \\
Drivers: renewables & 0.53 & 337 \\
Accompanying: awareness & 0.63 & 338 \\
Accompanying: subsidies for all & 0.18 & 338 \\
Accompanying: subsidies for poor & 0.25 & 338 \\
Accompanying: subsidies for rural & 0.1 & 338 \\
Accompanying: rebates for all & 0.25 & 338 \\
Accompanying: rebates for poor & 0.25 & 338 \\
Accompanying: rebates for rural & 0.07 & 338 \\
Accompanying: public transportation & 0.62 & 338 \\
\hline & &
\end{tabular}


Table 5 Policy perceptions and acceptability: summary statistics

\begin{tabular}{|c|c|c|}
\hline Variable & Mean & $N$ \\
\hline Effect on own behavior: less consumption & 0.56 & 338 \\
\hline Effect on own behavior: no change & 0.37 & 338 \\
\hline Effect on own behavior: more consumption & 0.07 & 338 \\
\hline Environmental effectiveness & 0.48 & 338 \\
\hline Co-benefit: better air quality (respondent and society) & 0.56 & 320 \\
\hline Co-benefit: less road congestion (respondent and society) & 0.27 & 320 \\
\hline Co-benefit: better health (respondent and society) & 0.42 & 320 \\
\hline Co-benefit: less road accidents (respondent and society) & 0.18 & 320 \\
\hline Drawback: less purchasing power & 0.67 & 338 \\
\hline Drawback: less comfort & 0.34 & 338 \\
\hline Drawback: fear of losing job & 0.05 & 338 \\
\hline Drawback: none & 0.22 & 338 \\
\hline Drawback: less purchasing power (society) & 0.69 & 338 \\
\hline Drawback: loss of competitiveness & 0.20 & 338 \\
\hline Drawback: distributional effects on the poor & 0.46 & 338 \\
\hline Drawback: rise in unemployment & 0.11 & 338 \\
\hline Acceptability & 0.49 & 338 \\
\hline Social cushioning: low income & 0.72 & 333 \\
\hline Social cushioning: middle income & 0.48 & 333 \\
\hline Social cushioning: high income & 0.14 & 333 \\
\hline Social cushioning: rural & 0.35 & 333 \\
\hline Social cushioning: urban & 0.19 & 333 \\
\hline Social cushioning: large families & 0.49 & 333 \\
\hline Social cushioning: elderly people & 0.58 & 333 \\
\hline Social cushioning: firms & 0.24 & 333 \\
\hline Revenue recycling: social cushioning (first) & 0.26 & 313 \\
\hline Revenue recycling: tax rebates (first) & 0.11 & 313 \\
\hline Revenue recycling: environmental projects (first) & 0.60 & 313 \\
\hline Acceptability when earmarking is specified & 0.64 & 337 \\
\hline Tax rate: $0 \%$ & 0.13 & 330 \\
\hline Tax rate: $0-5 \%$ & 0.30 & 330 \\
\hline Tax rate: $5-10 \%$ & 0.31 & 330 \\
\hline Tax rate: $10-15 \%$ & 0.16 & 330 \\
\hline Tax rate: $15-20 \%$ & 0.05 & 330 \\
\hline Tax rate: $20-25 \%$ & 0.02 & 330 \\
\hline Tax rate: $25-30 \%$ & 0.02 & 330 \\
\hline
\end{tabular}




\section{References}

Achtnicht M (2012) German car buyers' willingness to pay to reduce $\mathrm{CO}_{2}$ emissions. Clim Change 113(3-4):679-697

Baranzini A, Carattini S (2014) Taxation of emissions of greenhouse gases. In: Freedman B (ed) Global environmental change, Number 1 in Handbook of Global Environmental Pollution. Springer, Netherlands, pp 543-560

Baranzini A, Goldemberg J, Speck S (2000) A future for carbon taxes. Ecol Econ 32(3):395-412

Baranzini A, Thalmann P, Gonseth C (2004) Swiss climate policy: Combining VAs with other instruments under the menace of a $\mathrm{CO}_{2}$ tax. In: Baranzini A, Thalmann $\mathrm{P}$ (eds) Voluntary approaches in climate policy

Baranzini A, Weber S, Bareit M, Mathys NA (2013) The causal relationship between energy use and economic growth in Switzerland. Energy Econ 36:464-470

Baumol WJ, Oates WE (1971) The use of standards and prices for protection of the environment. Swed J Econ 73(1):42-54

Bazin D, Ballet J, Touahri D (2004) Environmental responsibility versus taxation. Ecol Econ 49(2):129-134

Becker GS, Murphy KM (1993) A simple theory of advertising as a good or bad. Q J Econ 108(4):941-964

Bolsen T, Leeper TJ, Shapiro MA (2014) Doing what others do norms, science, and collective action on global warming. Am Polit Res 42(1):65-89

Bornstein N, Lanz B (2008) Voting on the environment: price or ideology? Evidence from Swiss referendums. Ecol Econ 67(3):430-440

Bornstein N, Thalmann P (2008) 'I pay enough taxes already!' Applying economic voting models to environmental referendums. Soc Sci Q 89(5):1336-1355

Brännlund R, Ghalwash T (2008) The income-pollution relationship and the role of income distribution: an analysis of Swedish household data. Resour Energy Econ 30(3):369-387

Brannlund R, Persson L (2012) To tax, or not to tax: preferences for climate policy attributes. Clim Policy 12(6):704-721

Bristow AL, Wardman M, Zanni AM, Chintakayala PK (2010) Public acceptability of personal carbon trading and carbon tax. Ecol Econ 69(9):1824-1837

Brouwer R, Brander L, Beukering PV (2008) “A convenient truth”: air travel passengers' willingness to pay to offset their $\mathrm{CO}_{2}$ emissions. Clim Change 90(3):299-313

Bruvoll A, Larsen BM (2004) Greenhouse gas emissions in Norway: do carbon taxes work? Energy Policy 32(4):493-505

Buetler M, Maréchal MA (2007) Framing effects in political decision making: evidence from a natural voting experiment. CESifo Working Paper Series 1940, CESifo Group Munich

Carattini S (2015). Green consumers and climate policy: reconciling Ostrom and Nyborg, Howarth and Brekke. SSRN Scholarly Paper ID 2671328, Social Science Research Network

Carattini S, Baranzini A, Roca J (2015) Unconventional determinants of greenhouse gas emissions: the role of trust. Environ Policy Gov 25(4):243-257

Cherry TL, Kallbekken S, Kroll S (2012) The acceptability of efficiency-enhancing environmental taxes, subsidies and regulation: an experimental investigation. Environ Sci Policy 16:90-96

Cohen MA, Viscusi WK (2012) The role of information disclosure in climate mitigation policy. Clim Change Econ 03(04)

Deacon RT, Shapiro P (1975) Private preference for collective goods revealed through voting on referenda. Am Econ Rev 65(5):943-955

Deci EL, Ryan RM (1985) Intrinsic motivation and self-determination in human behavior. Springer, Berlin

Diederich J, Goeschl T (2013) Willingness to pay for voluntary climate action and its determinants: fieldexperimental evidence. Environmental and Resource Economics, pp 1-25

Dietz S, Marchiori C, Tavoni A (2012) Domestic politics and the formation of international environmental agreements. Working Paper 100, Centre for Climate Change Economics and Policy

Dresner S, Dunne L, Clinch P, Beuermann C (2006) Social and political responses to ecological tax reform in Europe: an introduction to the special issue. Energy Policy 34(8):895-904

Godal O, Holtsmark B (2001) Greenhouse gas taxation and the distribution of costs and benefits: the case of Norway. Energy Policy 29(8):653-662 
Goeschl T, Perino G (2012) Instrument choice and motivation: evidence from a climate change experiment. Environ Resour Econ 52(2):195-212

Gowdy JM (2008) Behavioral economics and climate change policy. J Econ Behav Organ 68(3-4):632-644

Greene WH (2011) Econometric analysis. Prentice Hall, New Jersey

Hahn RW (2009) Greenhouse gas auctions and taxes: some political economy considerations. Rev Environ Econ Policy 3(2):167-188

Howarth RB (2006) Optimal environmental taxes under relative consumption effects. Ecol Econ 58(1):209-219

IPCC (2014) Fifth assessment report-mitigation of climate change. Technical report

Kahneman D, Tversky A (2000) Choices, values, and frames. Cambridge University Press, Cambridge

Kallbekken S, Aasen M (2010) The demand for earmarking: results from a focus group study. Ecol Econ 69(11):2183-2190

Kallbekken S, Kroll S, Cherry TL (2011) Do you not like Pigou, or do you not understand him? Tax aversion and revenue recycling in the lab. J Environ Econ Manag 62(1):53-64

Kallbekken S, Sælen H (2011) Public acceptance for environmental taxes: self-interest, environmental and distributional concerns. Energy Policy 39(5):2966-2973

Lin B, Li X (2011) The effect of carbon tax on per capita $\mathrm{CO}_{2}$ emissions. Energy Policy 39(9):5137-5146

Lindman A, Ek K, Söderholm P (2013) Voluntary citizen participation in carbon allowance markets: the role of norm-based motivation. Clim Policy 13(6):680-697

Loeschel A, Sturm B, Vogt C (2013) The demand for climate protection-empirical evidence from Germany. Econ Lett 118(3):415-418

Longo A, Hoyos D, Markandya A (2012) Willingness to pay for ancillary benefits of climate change mitigation. Environ Resour Econ 51(1):119-140

Mathys NA, de Melo J (2011) Political economy aspects of climate change mitigation efforts. World Econ 34(11):1938-1954

Metcalf GE (2009) Designing a carbon tax to reduce U.S. greenhouse gas emissions. Rev Environ Econ Policy 3(1):63-83

Nyborg K, Howarth RB, Brekke KA (2006) Green consumers and public policy: on socially contingent moral motivation. Resour Energy Econ 28(4):351-366

OECD (2014) The cost of air pollution health impacts of road transport: health impacts of road transport. OECD Publishing

Ostrom E (2009) A polycentric approach for coping with climate change. Policy Research Working Paper Series, The World Bank

Owen AL, Videras J (2008) Trust, cooperation, and implementation of sustainability programs: the case of Local Agenda 21. Ecol Econ 68(1-2):259-272. doi:10.1016/j.ecolecon.2008.03.006

Pezzey JCV, Jotzo F (2013) Carbon tax needs thresholds to reach its full potential. Nat Clim Change 3(12):1008-1011

Pittel K, Rübbelke DTG (2008) Climate policy and ancillary benefits: a survey and integration into the modelling of international negotiations on climate change. Ecol Econ 68(1-2):210-220

Roca J (2003) Do individual preferences explain the environmental Kuznets curve? Ecol Econ 45(1):3-10

Roca J, Serrano M (2007) Income growth and atmospheric pollution in Spain: an input-output approach. Ecol Econ 63(1):230-242

Roe B, Teisl MF, Levy A, Russell M (2001) US consumers' willingness to pay for green electricity. Energy Policy 29(11):917-925

Sælen H, Kallbekken S (2011) A choice experiment on fuel taxation and earmarking in Norway. Ecol Econ 70(11):2181-2190

Sceia A, Altamirano-Cabrera J-C, Vielle M, Weidmann N (2012) Assessment of acceptable Swiss post2012 climate policies. Swiss J Econ Stat (SJES) 148(II):347-380

Sciarini P, Bornstein N, Lanz B (2007) The determinants of voting choices on environmental issues: a two-level analysis. In: de Vreese, C.H. (ed.) The dynamics of referendum campaigns. An international perspective. Palgrave Macmillan, pp 234-266

Spash CL, Lo AY (2012) Australia's carbon tax: a sheep in wolf's clothing? Econ Labour Relat Rev 23(1):67-85

Stadelmann-Steffen I (2011) Citizens as veto players: climate change policy and the constraints of direct democracy. Environ Polit 20(4):485-507

Steg L, Dreijerink L, Abrahamse W (2006) Why are energy policies acceptable and effective? Environ Behav 38(1):92-111 
Steg L, Vlek C (2009) Encouraging pro-environmental behaviour: an integrative review and research agenda. J Environ Psychol 29(3):309-317

Sterner T (ed) (2011) Fuel taxes and the poor: the distributional effects of gasoline taxation and their implications for climate policy. RFF Press

Thalmann P (2004) The public acceptance of green taxes: 2 million voters express their opinion. Public Choice 119:179-217

UNEP (2013) The emissions gap report 2013-a UNEP synthesis report

Zhang ZX, Baranzini A (2004) What do we know about carbon taxes? An inquiry into their impacts on competitiveness and distribution of income. Energy Policy 32(4):507-518 